\title{
The study of the latitudinal influence of geomagnetic conditions on variations of TECs over the territory of the Volga Federal District
}

\author{
Natalya Ryabova ${ }^{1}$, Aleksey Zuev ${ }^{1, *}$, Andrey Chernov ${ }^{1}$, and Evgeny Katkov ${ }^{1}$ \\ ${ }^{1}$ Volga State University of Technology, 424000, Yoshkar-Ola, Russia
}

\begin{abstract}
A comparative analysis of variations in the total electron content of the Earth's ionosphere over the territory of ten experimental stations located in the Volga region from December 2015 to November 2016 was carried out, taking into account the influence of geographic latitude and level of ionospheric disturbance.
\end{abstract}

\section{Introduction}

The widespread use of radio communications has led to a great interest in the ionosphere, as an environment through which information is transmitted. One of the main characteristics of the state of the ionosphere is the total electron content of the ionosphere (TEC). This paper discusses its variations, which can be both daily and seasonal [1-4].

\section{Objects of research and experiment technique}

Phase measurements at two frequencies of radionavigation signals were used to determine TEC [1]:

$$
I=\frac{1}{40,308} \frac{f_{1}^{2} f_{2}^{2}}{f_{1}^{2}-f_{2}^{2}}\left[\left(L_{1} \lambda_{1}-L_{2} \lambda_{2}\right)+\text { const }_{1,2}+\sigma L\right]
$$

where I - full electronic content; $\mathrm{L}_{1} \lambda_{1}$ and $\mathrm{L}_{2} \lambda_{2}$ - increments of the phase path of the radio signal due to phase delay in the ionosphere; $\mathrm{L}_{1}=\Delta \varphi / 2 \pi$ и $\mathrm{L}_{2}=\Delta \varphi / 2 \pi-$ phase measurements of a GPS / GLONASS receiver performed at frequencies $f_{1}$ and $f_{2}$ respectively (integer and fractional number of $\pi$-phase cycles); const $t_{1,2}$ - ambiguity of phase measurements; $\sigma \mathrm{L}$ - phase measurement error.

When estimating the amplitude of TEC variations, the following processing order is used. The initial data are the rows of the "inclined" TEC, as well as the corresponding values of the elevation angle for the beam "NS - receiver". Further, the zero-order trend due to phase ambiguity is removed from the "vertical" TEC series.

After removing the ambiguity of the phase measurements, a number of measurements of TEC - remains, which contains a trend of the first order, including the daily variation of the TEC, as well as changes in the TEC due to satellite flight. To isolate ionospheric

*Corresponding author: ZuevAV@,volgatech.net 
disturbances of a given time scale, it is necessary to remove this trend from the series of measurements. From the initial series of TEC, the site of observations between the moments of time $\mathrm{t} 1, \mathrm{t} 2$, which corresponds to the ionospheric disturbance of a given time scale, is removed. The series of measurements obtained in this way is approximated by a third-order polynomial using the least squares method. The series obtained in this way is subtracted from the initial series of observations, as a result of which a series of TEC measurements is obtained with a first order trend removed. We will measure this series, since it evaluates small oscillations of the TEC. They are also measured in TECU. When evaluating TEC, it usually represents dozens of TECU, TEC variations are measured in decimal TECU values to 1 TECU. Large oscillations of TECs mainly respond only to impacts from space (magnetic storms, flashes, etc.). TEC variations are more sensitive, they react both to this and to processes occurring on our planet (typhoons, earthquakes, etc.). Accordingly, if the jumps of these fluctuations are not explained by causes outside the Earth, it means in this area there is an impact on the ionosphere associated, for example, with some small earthquakes inherent in some mountainous terrain.

Next, we analyzed the dynamics of the intensity of TEC oscillations under quiet conditions and with disturbances in the Earth's magnetic field for different seasons of the year. The technique included filtering TEC variations in order to isolate fluctuations with periods of not more than 20 minutes [3].

When assessing the amplitude of TEC variations [3], a zero order trend due to phase ambiguity was removed from the TEC time series. After removing phase measurement ambiguity, a series of TEC data, including the first order trend, was left, and it was also removed. TEC variations were measured in TECU.

When estimating the amplitude of TEC variations [3], a zero order trend, associated with phase ambiguity, was removed from the TEC time series. After that, the TEC data series, including the first order trend, was left, and it was also removed at the next stage of processing. TEC variations were measured at TECU.

The obtained data are separated by the level of perturbation of the Earth's magnetic field and the seasons of the year.

The level of magnetic field perturbation was estimated by the $\mathrm{Kp}$-index value. This index is calculated according to the data of the Physical Institute of the Russian Academy of Sciences presented for general use on the official website of the Institute. Certainly, those days for which the Kp-index did not exceed 3 were considered calm days. The data were related to a magnetic storm, if $\mathrm{Kp}>5$.

\section{The results of experimental studies}

The paper analyzed the experimental data obtained from navigation measurements of the Navgeokom SmartNetRussia reference station network (currently, the company has been renamed Hexagon). Table 1 below presents the results of calculations of the maximum and minimum values of average daily variations of TEC in different seasons from December 2015 to November 2016, taking into account the influence of geographic latitude based on experimental data from the network of reference stations SmartNetRussia.

\section{Conclusion}

During the study, the following results were obtained:

The greatest increase in TEC variations under the influence of magnetic storms was observed in spring over the reference station Nizhny Novgorod (an increase of 2.83 times relative to the unexcited ionosphere), in the summer and winter periods over the territory of the city of Perm (an increase of 1.94 times and 1.42 times, respectively), in autumn - over the territory of the city of Samara (an increase of 3.54 times). 
The smallest increase in TEC variations under the influence of magnetic storms was observed in the spring period over the territory of the city of Orenburg (an increase of 1.38 times relative to the unexcited ionosphere), in the summer period over the territory of the Sergievsk settlement (an increase of 1.33 times), in the autumn period over the territory of the city of Ufa (an increase of 2 times), in winter - over the territory of the city of Orenburg (practically without changes in the relatively unexcited ionosphere).

Table 1. The results of calculations of TEC variations.

\begin{tabular}{|c|c|c|c|c|c|c|c|c|c|}
\hline City name & $\begin{array}{c}\text { Coordi- } \\
\text { nates } \\
\text { (north } \\
\text { latitude) }\end{array}$ & \begin{tabular}{|c|} 
Maximu \\
m \\
value of \\
daily \\
average \\
TEC \\
variatio \\
ns for \\
spring \\
\end{tabular} & \begin{tabular}{|c|} 
Minimu \\
m \\
value of \\
daily \\
average \\
TEC \\
variatio \\
ns for \\
spring \\
\end{tabular} & \begin{tabular}{|c} 
Maximu \\
m \\
value of \\
daily \\
average \\
TEC \\
variatio \\
ns for \\
summer
\end{tabular} & \begin{tabular}{|c|} 
Minimu \\
m \\
value of \\
daily \\
average \\
TEC \\
variatio \\
ns for \\
summer
\end{tabular} & \begin{tabular}{|c|} 
Maximu \\
m \\
value of \\
daily \\
average \\
TEC \\
variatio \\
ns for \\
autumn
\end{tabular} & $\begin{array}{c}\text { Minimu } \\
\text { m } \\
\text { value of } \\
\text { daily } \\
\text { average } \\
\text { TEC } \\
\text { variatio } \\
\text { ns for } \\
\text { autumn }\end{array}$ & \begin{tabular}{|c|} 
Maximu \\
m \\
value of \\
daily \\
average \\
TEC \\
variatio \\
ns for \\
winter
\end{tabular} & $\begin{array}{c}\text { Minimum } \\
\text { value of } \\
\text { daily } \\
\text { average } \\
\text { TEC } \\
\text { variations } \\
\text { for winter }\end{array}$ \\
\hline Oren & $51^{\circ} 46^{\prime} 00^{\prime \prime}$ & 0,051 & 0,037 & 0,035 & 0,026 & 0,056 & 0,022 & 0,042 & 0,044 \\
\hline Sizran & $53^{\circ} 10^{\prime} 00^{\prime \prime}$ & 0,047 & 0,027 & 0,030 & 0,021 & 0,045 & 0,014 & 0,037 & 0,038 \\
\hline Same & $53^{\circ} 11^{\prime} 00^{\prime \prime}$ & 0,047 & 0,024 & 0,028 & 0,020 & 0,046 & 0,013 & 0,036 & 0,037 \\
\hline Sergiyevsk & $53^{\circ} 56^{\prime} 53^{\prime \prime}$ & 0,050 & 0,026 & 0,032 & 0,024 & 0,048 & 0,0120 & 0,042 & 0,033 \\
\hline Saransk & $54^{\circ} 11^{\prime} 00^{\prime \prime}$ & 0 & 0 , & 0,027 & 0,018 & 0,041 & 12 & 0,038 & 0,040 \\
\hline Ufa & $54^{\circ} 44^{\prime} 00^{\prime \prime}$ & 0,050 & 0,035 & 0,038 & 0,028 & 0,054 & 0,027 & 0,051 & 0,045 \\
\hline Cheboksary & $56^{\circ} 07^{\prime} 00^{\prime \prime}$ & 0,052 & 0,022 & 0,029 & 0,018 & 0,041 & 0,015 & 0,046 & 0,037 \\
\hline Nizhny & $56^{\circ} 19^{\prime} 37^{\prime \prime}$ & 0,051 & 0,018 & 0,027 & 0,016 & 0,040 & 0,013 & 0,043 & 0,038 \\
\hline $\begin{array}{l}\text { Yoshkar- } \\
\text { Ola }\end{array}$ & $56^{\circ} 37$ & 0,056 & 0,023 & 31 & 0,022 & 0,044 & 0,020 & 0,050 & 0,038 \\
\hline Permian & $58^{\circ} 00^{\prime} 50^{\prime \prime}$ & 0,064 & 0,024 & 0,035 & 0,018 & 0,044 & 0,020 & 0,047 & 0,033 \\
\hline
\end{tabular}

\section{Acknowledgment}

This work was supported by a grant from Ministry of Science and Higher Education of the Russian Federation: № 3.4074.2017/PC and grants from Russian Foundation for Basic Research: № 18-07-01377, № 17-07-01590.

\section{References}

1. E.L. Afraimovich, N.P. Perevalova, GPS monitoring of the Earth's upper atmosphere, Irkutsk (Russia): Publisher GU NTS RVH VSNTS SB RAMS, 480 p. (in Russian) (2006)

2. Yu. V.Yasyukevich, A. A. Mylnikova, V. V. Demyanov, V. A. Ivanov, N. V. Ryabova, A. V. Zuev, M. I. Ryabova, A. A. Kislitsyn, "Daily dynamics of the vertical total electronic content over the cities of Irkutsk and Yoshkar-Ola according to GPS / GLONASS data and the IRI-2012 model", Yoshkar-Ola (Russia): Bulletin of the Volga State University of Technology. Ser.: Radio and infocommunication systems., no.3., pp.18-29 (in Russian) (2013) 
3. V. V. Demyanov, Yu. V. Yasyukevich, Mechanisms of the impact of irregular geophysical factors on the functioning of satellite radio navigation systems: monograph, Irkutsk (Russia): ISU, 349 p. (in Russian) (2014)

4. V.A. Ivanov, A.Yu. Zhelonkin, N.V. Ryabova, A.V. Zuev, "Influence of geomagnetic disturbances on the total electronic content of the ionosphere, Yoshkar-Ola (Russia): Bulletin of the Mari State Technical University". Ser.: Radio and infocommunication systems, no.1., pp. 24-30 (in Russian) (2011) 